\title{
洪泽湖轮虫群落结构及其与环境因子的关系”
}

\author{
都雪 ${ }^{1,2}$, 王齐东 ${ }^{1,2}$, 张超文 ${ }^{1,2}$, 李 为 $^{1}$, 冯伟松 ${ }^{1}$, 张堂林 ${ }^{1}$, 刘家寿 ${ }^{1}$, 李钟杰 ${ }^{1 * *}$ \\ (1:中国科学院水生生物研究所淡水生态与生物技术国家重点实验室,武汉 430072) \\ (2: 中国科学院大学, 北京 100049)
}

摘 要: 2010 年 5 月至 2011 年 2 月对洪泽湖轮虫进行季度采样, 分析了洪泽湖轮虫的种类组成、时空分布及其群落结构 与环境因子的关系. 结果表明, 洪泽湖共观察到轮虫 17 属 34 种, 优势种为螺形龟甲轮虫 (Keratella cochlearis)、前节晶囊轮 虫 (Asplanchna priodonta)、长肢多肢轮虫 (Polyarthra dolichoptera)、颌花臂尾轮虫 (Brachionus calyciflorus) 和曲腿龟甲轮虫 (Keratella valga). 轮虫种类的空间分布格局呈现较大差异,种类数在北部成子湖最高 (27 种), 西南部湖区次之 ( 26 种), 东部沿岸带最低 (19 种) ; 而密度则表现为西南部湖区略高于成子湖, 东部沿岸带最低. 轮虫的群落结构季节差异明显, 密 度和生物量在春季最高, 秋季次之, 而夏季最低. 典范对应分析结果表明, 水温、溶解氧及叶绿素 a 等因子对轮虫种类的季 节变化及密度生物量的影响最大; 总磷、总氮及可溶性无机氮等水体中的营养盐也是影响轮虫群落结构的重要因素.

关键词: 轮虫;群落结构;环境因子;洪泽湖;典范对应分析

\section{Community structure of rotifers in relation to environmental factors in Lake Hongze}

\author{
DU Xue ${ }^{1,2}$, WANG Qidong ${ }^{1,2}$, ZHANG Chaowen ${ }^{1,2}$, LI Wei ${ }^{1}$, FENG Weisong ${ }^{1}$, ZHANG Tanglin ${ }^{1}$, LIU Jiash- \\ ou $^{1} \&$ LI Zhongjie ${ }^{1}$ \\ (1: State Key Laboratory of Freshwater Ecology and Biotechnology, Institute of Hydrobiology, Chinese Academy of Sciences, \\ Wuhan 430072 , P. R. China) \\ (2: University of Chinese Academy of Sciences, Beijing 100049, P. R. China)
}

\begin{abstract}
The spatial-temporal changes in rotifer species composition and community structure and their relationship with key environmental factors were investigated seasonally from May 2010 ( spring) to February 2011 (winter) in a shallow freshwater lake, Lake Hongze, China. Totally 34 species of rotifer, belonging to 17 genera, were identified during the seasonal sampling. Keratella cochlearis, Asplanchna priodonta, Polyarthra dolichoptera, Brachionus calyciflorus and Keratella valga were the dominant species. Lake Hongze has three main areas that are Chengzihu, southwest and east area. The rotifer distribution in the three main areas was significantly different. There were 27, 26 and 19 species in Chengzihu, southwest, east area, respectively. Meanwhile, the maximum density and biomass of rotifers was found in the southwest area of Lake Hongze while the minimum was found in the east area. In terms of seasonal variation, the density and biomass of rotifer was highest in spring, with higher values in autumn. The density and biomass in summer was lowest in the four seasons. Their relationship with environmental factors was analyzed using canonical correspondence analysis (CCA). From the result of CCA, environmental factors such as water temperature, dissolved oxygen and chlorophyll-a that representing seasonal variations of water quality were significantly correlated with the Axis 1 and affected the composition and the density of rotifer community. Moreover, environmental factors related to nutrient concentrations such as total phosphorus, total nitrogen and dissolved inorganic nitrogen were also important nutrient factors which influenced the community structure of rotifer of Lake Hongze.
\end{abstract}

Keywords: Rotifer; community structure; environmental factors; Lake Hongze; CCA

* 公益性行业(农业)科研专项项目(200903048-04)、国家自然科学基金项目 (30830025) 和淮安市科技支撑计划项 目 (IHB/CN/2009103) 联合资助. 2012-12-25 收稿;2013-09-28 收修改稿. 都雪 (1985 ), 女, 博士研究生; Email:dux@ihb.ac.cn.

** 通信作者;E-mail: zhongjie@ihb. ac.cn. 
轮虫是淡水生态系统中重要的浮游动物种类之一. 轮虫个体小, 发育时间快, 生命周期短 ${ }^{[1]}$, 生产力比 甲壳类浮游动物高, 在维持水生态系统结构和功能的完整性以及贡献水体次级生产力等方面具有重要意 $义^{[2]}$. 同时, 轮虫处于食物网的中间环节, 它一方面可以作为捕食者调控浮游植物、原生动物和细菌等生物 的数量, 另一方面可以作为鱼类的开口饵料和食物来源, 在水生态系统的物质循环和能量流动过程中发挥 重要作用 ${ }^{[3-4]}$. 此外, 轮虫对环境反应敏感, 常常作为水体的指示生物, 因此在评价水体营养状态和水体污染 状况等方面受到广泛关注 ${ }^{[5-7]}$. 已有研究表明轮虫的多样性是水域生态系统服务功能的重要评价指标之一, 其种类组成和生物量的变化能及时准确反映水域生态环境质量的优劣 ${ }^{[6,8]}$. 一般而言, 湖泊中轮虫群落结构 的时空变化受生物及非生物因素的共同影响, 非生物因素主要包括温度、 $\mathrm{pH}$ 、溶解氧等, 而食物资源、捕食与 竞争是重要的生物因素 ${ }^{[9-11]}$.

洪泽湖是我国第四大淡水湖, 地处江苏省西部淮河下游, 由于其独特的地理位置和区域优势, 成为南水 北调东线工程的中转平台和重要的调蓄过水通道, 在防洪、调节气候、保护生物多样性以及渔业等方面起着 极其重要的作用. 但近年来, 受淮河及湖泊周围地区的环境污染和人类活动的影响, 洪泽湖生态系统呈现退 化趋势 ${ }^{[12]}$. 相比于我国其他大型淡水湖泊, 对于洪泽湖的水生生物资源和水生态环境等方面的研究还远远 不够, 目前已有的研究仅仅涉及洪泽湖的水质理化特征、水生植被等方面 ${ }^{[13-15]}$, 而关于洪泽湖轮虫群落结构 特征及其影响因素的研究鲜有报道. 因此, 本研究于 2010 年 5 月至 2011 年 2 月逐季对洪泽湖轮虫群落结构 进行调查, 通过分析轮虫的种类组成、密度、生物量和生物多样性的周年动态变化, 并探讨洪泽湖轮虫群落 结构与水质环境因子之间的关系, 以期为洪泽湖水环境评价和渔业资源的合理开发利用提供一定的理论 依据.

\section{1 材料与方法}

\section{1 研究区域概况}

洪泽湖 ( $33^{\circ} 06^{\prime} \sim 33^{\circ} 40^{\prime} \mathrm{N}, 118^{\circ} 10^{\prime} \sim 118^{\circ} 52^{\prime} \mathrm{E}$ ) 位于江苏省西部淮河下游, 水域面积 $1597 \mathrm{~km}^{2}$ ( 水位 $12.5 \mathrm{~m}$ ). 洪泽湖西承淮河, 东通黄海, 南注长江, 北连沂、沭、泗诸水系 ${ }^{[16]}$. 洪泽湖自 $1990 \mathrm{~s}$ 以来污染有加大 趋势, 人湖污染物总量已超过湖泊的自净能力, 总氮、总磷和高镇酸盐指数已达到中度富营养化水平并有高 度富营养化的趋势 ${ }^{[13]}$.

\section{2 样点设置与采样时间}

洪泽湖由成子湖及洪泽湖大湖区组成, 由于营养盐补给主要来源于洪泽湖西南部及成子湖人湖河流, 因此本研究又对洪泽湖按照东部沿岸带、成子湖及洪泽湖西南部 3 个水域对轮虫进行分析. 全湖设置 20 个 采样点 (图 1), 可划分为 3 个区域:东部沿岸带 (采样点 1 4、18 20)、成子湖区 (采样点 5 11) 及西南部 区域(采样点 $12 \sim 17$ ). 2010-2011 年分季度采样, 时间分别为 2010 年 5 月 9 日 (春季)、2010 年 8 月 9 日 (夏季)、2010 年 11 月 9 日(秋季)和 2011 年 2 月 22 日 (冬季).

\section{3 样本的采集与测定}

利用 Secchi Disk 透明度盘现场测量水深 (WD) 和透明度 (SD). 水温 (WT)、溶解氧 (DO)、pH 及电导率 (Conductivity) 等指标采用 YSI85 多参数水质测量仪现场测定. 用 $5 \mathrm{~L}$ 有机玻璃采水器于表层 $(0 \sim 50 \mathrm{~cm})$ 采 集水样. 叶绿素 $\mathrm{a}$ (Chl. a) 采用 $90 \%$ 丙酮萃取法测定; 总磷 (TP) 和总氮 (TN) 含量分别采用锄酸铵分光光度 法及碱性过硫酸钾消解紫外分光光度法测定; 高锰酸盐指数 $\left(\mathrm{COD}_{\mathrm{Mn}}\right)$ 、可溶性磷酸盐 ( SRP) 和溶解无机氮 $\left(\mathrm{DIN}=\right.$ 铵态氮 $\left(\mathrm{NH}_{4}^{+}-\mathrm{N}\right)+$ 亚硝态氮 $\left(\mathrm{NO}_{2}^{-}-\mathrm{N}\right)+$ 硝态氮 $\left.\left(\mathrm{NO}_{3}^{-}-\mathrm{N}\right)\right)$ 参照 《水和废水监测分析方法》 $($ 第四版 $)$ 测定 ${ }^{[17]}$. 野外样品的采集参照《湖泊生态调查观测与分析》 ${ }^{[18]}$ 进行.

分层采集 $1 \mathrm{~L}$ 混合水样并加人少许福尔马林固定, 沉淀 $48 \mathrm{~h}$ 后吸取上清液浓缩定容至 $30 \mathrm{ml}$ 后用于轮 虫定量样本的鉴定与计数, 根据近似几何图形, 按求积公式获得轮虫体积, 并假定比重为 1 , 求得生物量. 轮 虫的鉴定、计数及生物量测定方法参考文献 $[19,21]$.

\section{4 数据处理}

典范对应分析 (CCA) 用于分析轮虫群落与水体环境参数之间的关系. CCA 是一种非线性多元直接梯度 分析方法, 它在对应分析的迭代过程中要求两个数据矩阵, 即物种数据矩阵及环境数据矩阵. 用于 CCA 分析 


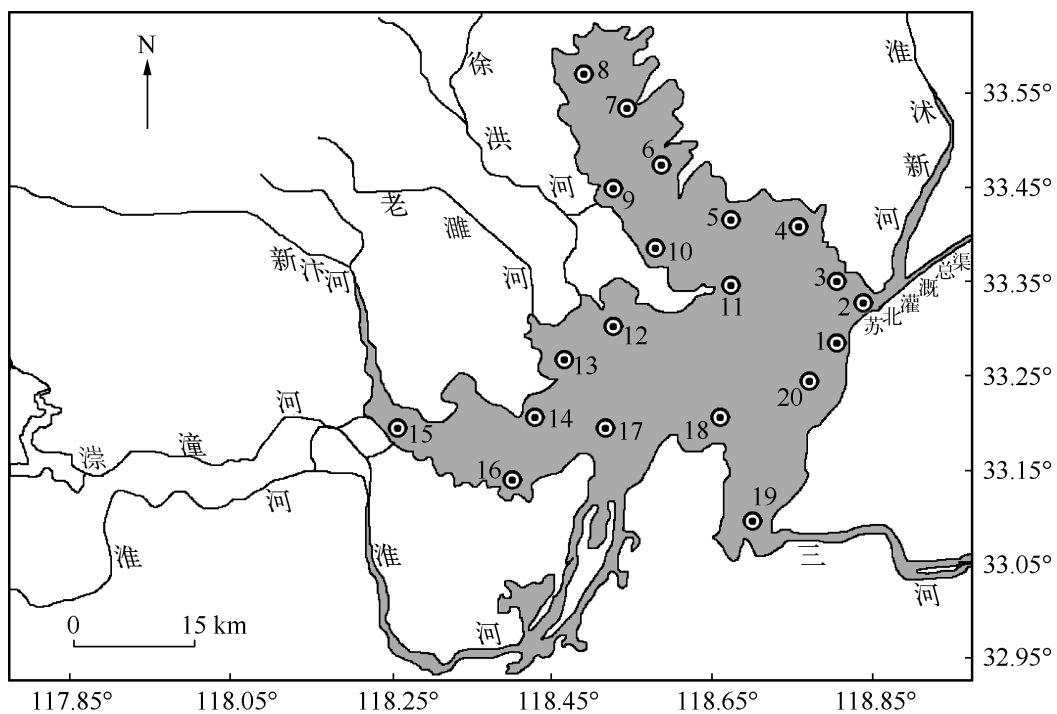

图 1 洪泽湖采样点分布

Fig. 1 Distribution of sampling sites in Lake Hongze

的物种在该采样点的相对密度 $\geqslant 1 \%$. 数据分析前, 将轮虫密度及环境数据进行 $\lg (x+1)$ 转化处理, 使数据 接近正态化分布. Monte Carlo 检验 (999 次非限制型转置) 用于检验环境因子与物种组成之间的相关性. CCA 应用 R 软件“ade4”数据包进行分析并得出物种与环境二维排序图.

\section{2 结果}

\section{1 水体理化因子}

洪泽湖春、夏、秋、冬 4 个季节各采样点水体理化因子平均值存在季节差异: 春季, WD、 $\mathrm{SD} 、 \mathrm{pH}$ 、电导率、 TN 和 DIN 含量最高, $\mathrm{COD}_{\mathrm{Mn}}$ 、TP 和 SRP 含量最低; 夏季, WT 和 Chl. a 含量最高, DO 、TN 及 DIN 含量最低; 秋 季, Chl. a 含量最低; 冬季, DO、SRP、TP 和 $\mathrm{COD}_{\mathrm{Mn}}$ 含量最高, $\mathrm{pH}$ 、电导率和 $\mathrm{WT}$ 最低 (表 1).

表 1 洪泽湖理化因子的季节变化

Tab. 1 Seasonal changes of physicochemical factors in Lake Hongze

\begin{tabular}{|c|c|c|c|c|}
\hline 理化因子 & 春季 & 夏季 & 秋季 & 冬季 \\
\hline $\mathrm{WD} / \mathrm{cm}$ & $256 \pm 25$ & $204 \pm 22$ & $223 \pm 21$ & $193 \pm 11$ \\
\hline $\mathrm{WT} /{ }^{\circ} \mathrm{C}$ & $20.1 \pm 0.1$ & $31.9 \pm 0.3$ & $14.1 \pm 0.2$ & $6.1 \pm 0.1$ \\
\hline $\mathrm{SD} / \mathrm{cm}$ & $73 \pm 7$ & $45 \pm 10$ & $47 \pm 7$ & $55 \pm 8$ \\
\hline $\mathrm{pH}$ & $8.80 \pm 0.08$ & $8.57 \pm 0.09$ & $8.00 \pm 0.02$ & $7.68 \pm 0.01$ \\
\hline $\mathrm{DO} /(\mathrm{mg} / \mathrm{L})$ & $10.19 \pm 0.21$ & $7.23 \pm 0.39$ & $9.74 \pm 0.15$ & $11.56 \pm 0.35$ \\
\hline 电导率/ $(\mu \mathrm{S} / \mathrm{cm})$ & $588 \pm 30$ & $432 \pm 23$ & $390 \pm 21$ & $351 \pm 5$ \\
\hline $\mathrm{COD}_{\mathrm{Mn}} /(\mathrm{mg} / \mathrm{L})$ & $4.78 \pm 0.20$ & $4.85 \pm 0.12$ & $4.78 \pm 0.24$ & $5.88 \pm 0.38$ \\
\hline $\mathrm{TP} /(\mathrm{mg} / \mathrm{L})$ & $0.064 \pm 0.011$ & $0.095 \pm 0.008$ & $0.089 \pm 0.012$ & $0.101 \pm 0.009$ \\
\hline $\mathrm{SRP} /(\mathrm{mg} / \mathrm{L})$ & $0.011 \pm 0.002$ & $0.018 \pm 0.004$ & $0.019 \pm 0.005$ & $0.019 \pm 0.005$ \\
\hline $\mathrm{TN} /(\mathrm{mg} / \mathrm{L})$ & $1.88 \pm 0.16$ & $1.06 \pm 0.10$ & $1.21 \pm 0.14$ & $1.32 \pm 0.18$ \\
\hline $\mathrm{DIN} /(\mathrm{mg} / \mathrm{L})$ & $1.91 \pm 0.19$ & $1.06 \pm 0.11$ & $1.20 \pm 0.19$ & $1.30 \pm 0.19$ \\
\hline Chl. a/ $(\mu \mathrm{g} / \mathrm{L})$ & $17.3 \pm 2.8$ & $20.1 \pm 3.7$ & $8.6 \pm 1.2$ & $16.0 \pm 2.2$ \\
\hline
\end{tabular}

\section{2 轮虫的种类组成}

洪泽湖四季水体样本中共观察到轮虫 18 属 34 种 (表 2), 成子湖湖区的轮虫种类数 (27 种) 接近于西南 
部湖区 (26 种), 均高于东部沿岸带轮虫种类数 (19 种). 优势种为螺形龟甲轮虫、前节晶囊轮虫、长肢多肢轮 虫、䓵花臂尾轮虫及曲腿龟甲轮虫.

表 2 洪泽湖轮虫种类组成

Tab. 2 Species composition of rotifers in Lake Hongze

\begin{tabular}{|c|c|c|c|c|}
\hline 种类 & 缩写 & 东部沿岸带 & 西南部湖区 & 成子湖湖区 \\
\hline 螺形龟甲轮虫 Keratella cochlearis & Kcoch & + & + & + \\
\hline 矩形龟甲轮虫 $K$. quadrata & Kquad & + & + & + \\
\hline 曲腿龟甲轮虫 $K . v a l g a$ & Kvalg & + & + & + \\
\hline 广布多肢轮虫 Polyarthra vulgaris & Pvulg & + & + & + \\
\hline 长肢多肢轮虫 $P$. dolichoptera & Pvulg & + & + & + \\
\hline 圆筒异尾轮虫 Trichocerca cylindrical & Tcyli & & & + \\
\hline 长刺异尾轮虫 $T$. longiseta & Tlong & + & & + \\
\hline 二突异尾轮虫 $T$. bicristata & Pdoli & & & + \\
\hline 暗小异尾轮虫 $T$. pusilla & Tpusi & + & + & + \\
\hline 纵长异尾轮虫 $T$. elongata & Telon & + & + & + \\
\hline 等刺异尾轮虫 $T$. similis & Tsimi & + & + & + \\
\hline 罗氏异尾轮虫 $T$. rousseleti & Trous & & + & + \\
\hline 营花臂尾轮虫 Brachionus calyciflorus & Bcaly & + & + & + \\
\hline 镰状臂尾轮虫 $B$. falcatus & Bfalc & & + & \\
\hline 裂足臂尾轮虫 $B$. diversicornis & Bdive & + & + & + \\
\hline 角突臂尾轮虫 $B$. angularis & Bangu & + & + & + \\
\hline 壸状臂尾轮虫 B. urceus & Burce & + & + & + \\
\hline 剪形臂尾轮虫 $B$. forficula & Bforf & & + & \\
\hline 前节晶囊轮虫 Asplanchna priodonta & Aprio & + & + & + \\
\hline 卜氏晶囊轮虫 A. brightwelli & Abrig & & + & \\
\hline 真足哈林轮虫 Harringia eupoda & Heupo & & + & + \\
\hline 大肚须足轮虫 Euchlanis dilatata & Edila & & + & \\
\hline 顶生三肢轮虫 Filinia terminalis & Flong & + & & \\
\hline 长三肢轮虫 $F$. longiseta & Flong & + & + & + \\
\hline 梳状病毛轮虫 Synchaeta pectinata & Spect & & & + \\
\hline 疮毛轮虫属某种 Synchaeta sp. & Sync & & + & + \\
\hline 十指平甲轮虫 Platyias militaris & Pmili & & & + \\
\hline 独角聚花轮虫 Conochilus unicornis & Cunic & & & + \\
\hline 唇形叶轮虫 Notholca labis & Nlabi & + & + & + \\
\hline 方块鬼轮虫 Trichotria tetractis & Ttetr & & & + \\
\hline 奇异六腕轮虫 Hexarthra mira & Hmira & + & + & + \\
\hline 共趾腔轮虫 Lecane syinpoda & Lsyin & + & + & + \\
\hline 郝氏皱甲轮虫 Ploesoma hudsoni & Phuds & & + & \\
\hline 没尾无柄轮虫 Ascomorpha ecaudis & Aecau & & + & \\
\hline
\end{tabular}

螺形龟甲轮虫和长肢多肢轮虫为春季优势种, 分别占总密度的 $80.3 \%$ 和 $10.6 \%$. 夏季, 轮虫优势种主要 为异尾轮虫. 异尾轮虫属占总密度的 $45.0 \%$, 其中, 尤以暗小异尾轮虫和等刺异尾轮虫所占比例最高, 分别 占总密度的 $26.5 \%$ 和 $14.7 \%$, 曲腿龟甲轮虫和奇异六腕轮虫也分别以所占比例 $18.2 \%$ 和 $14.7 \%$ 成为优势 种. 秋、冬季, 轮虫群落的优势种为龟甲轮虫和长肢多肢轮虫, 其中螺形龟甲轮虫在秋、冬季的密度百分比小 于春季,分别为 $44.5 \%$ 和 $17.1 \%$ (图 2).

\section{3 轮虫的密度及生物量}

洪泽湖轮虫年平均密度和生物量分别为 323.6 ind. $/ \mathrm{L}$ 和 $0.388 \mathrm{mg} / \mathrm{L}$, 各季节平均密度差异较大 (Kruskall-Wallis test, $n=76, \mathrm{~d} f=3, P=0.042$ ), 春季 ( 5 月) 平均密度和生物量最高, 夏季 ( 8 月) 最低 (图 
3a). 从空间分布来看, 各区域轮虫的平均密 度也存在显著差异 (Kruskall-Wallis test, $n=$ $76, \mathrm{~d} f=3, P=0.003)$, 洪泽湖西南部湖区和 成子湖湖区的轮虫平均密度和生物量均高于 东部沿岸带 (图 3b).

\section{4 环境因子对轮虫群落结构的影响}

CCA 分析结果显示, 前两个轴的特征值 分别为 0.493 和 0.171 , 前两轴环境因子的解 释率分别为 $38.13 \%$ 和 $13.24 \%$. WT 及 DO 与 第一轴的正、负相关性最高,因此第一轴可以

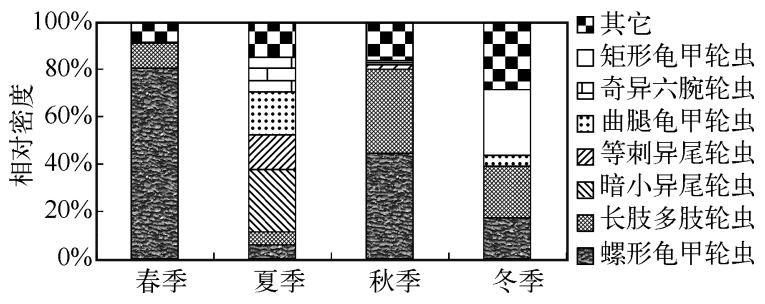

图 2 洪泽湖各季节轮虫优势种密度的季节变化

Fig. 2 Seasonal variation of abundance of the dominant rotifer species in Lake Hongze 代表环境因子的季节性变化;电导率、 $\mathrm{pH}$ 及 氮、磷等营养物质与第二轴相关, 因此第二轴与水体的营养状况有关 (图 4).

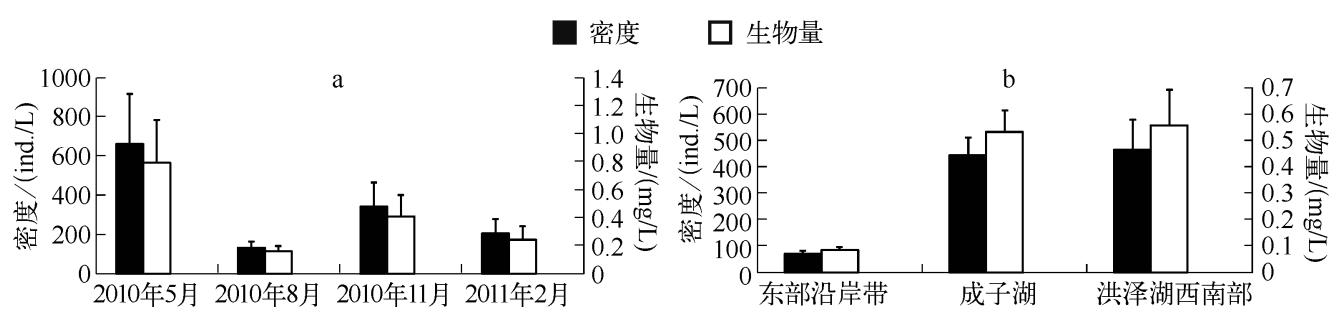

图 3 洪泽湖轮虫密度及生物量的时空变化

Fig. 3 Seasonal and spatial variation of density and biomass of rotifer in Lake Hongze

从各季节的采样点分布来看 (图 4), 水温在第一轴上解释率最高, 而夏季轮虫的优势种主要为异尾轮虫 及奇异六腕轮虫, 这些物种也均集中在 CCA 排序图的右侧, 与 WT、Chl. a 及 TP 密切相关. 螺形龟甲轮虫和 长肢多肢轮虫处于 CCA 坐标轴的原点附近, 这两个物种在春、秋和冬季的相对生物量均较高. CCA 图形中 左上部分的物种大部分为冬季优势种,如唇形叶轮虫等,这些物种与 DO 呈正相关而与 WT 呈负相关, 说明 这些轮虫需要较高的溶解氧及可以生存在低温的环境下.

\section{3 讨论}

通过洪泽湖 4 个季节的采样, 共鉴定出轮虫 34 种, 轮虫种类数比 1989 年的调查结果少 3 种 ${ }^{[20]}$, 虽然轮 虫的种类数变化不大, 但从种类组成上来看,一些经常出现在沉水植物丰富的水体中的轮虫种类消失, 如腹 棘管轮虫 (Mytlina ventralia)、台氏合甲轮虫 (Diploris daviesiae)、月形单趾轮虫 (Monostyla lunaris)、盘镜轮虫 (Testudinella patina $)^{\text {等 }}{ }^{[21]}$. 造成这些物种消失的原因可能是由于 $1989-2010$ 年间, 洪泽湖的沉水植物覆盖 率下降, 水体富营养化程度加剧, 进而导致轮虫群落的种类组成发生变化. 春季轮虫种类数较少, 螺形龟甲 轮虫大量繁殖, 成为绝对优势种. 夏季异尾轮虫成为优势种, 种类数较春季增多且种群数量更为平均, 说明 夏季轮虫群落结构较春季更为稳定. 秋、冬季, 螺形龟甲轮虫和长肢多肢轮虫又成为绝对优势种. 从优势种 的变化可以看出洪泽湖轮虫群落的季节演替.

研究结果显示, 轮虫密度及生物量在春、秋季高于夏、冬季, 这与 Devetter ${ }^{[22]}$ 的研究结果一致, 伴随着两 个高峰出现的是浮游植物生物量 (Chl. a) 的下降和水体透明度的升高. 很多学者认为不同季节轮虫群落演 替的主要原因是水温的变化 ${ }^{[23-24]}$. 洪泽湖位于北亚热带与暖温带交界处, 季风盛行, 四季分明, 温度变化明 显, 温度必然成为影响轮虫密度变化的影响因素之一 ${ }^{[25]}$. 春季水温开始升高, 提高了轮虫休眠卵的孵化率, 缩短了卵的捊化时间, 轮虫繁殖力的增加提高了轮虫种群的周转速率, 从而形成了轮虫春季的密度高峰 ${ }^{[26]}$. 夏季水温继续升高, 但溶解氧往往成为限制轮虫群落生长的主要影响因子. 通常认为,水温的升高会致使蓝 藻水华的暴发 ${ }^{[27]}$, 藻类的过度繁殖会增加水体有机物的呼吸作用, 同时死亡藻类的分解作用也会降低水体 的溶解氧, 进而影响轮虫的群落结构 ${ }^{[28]}$. 


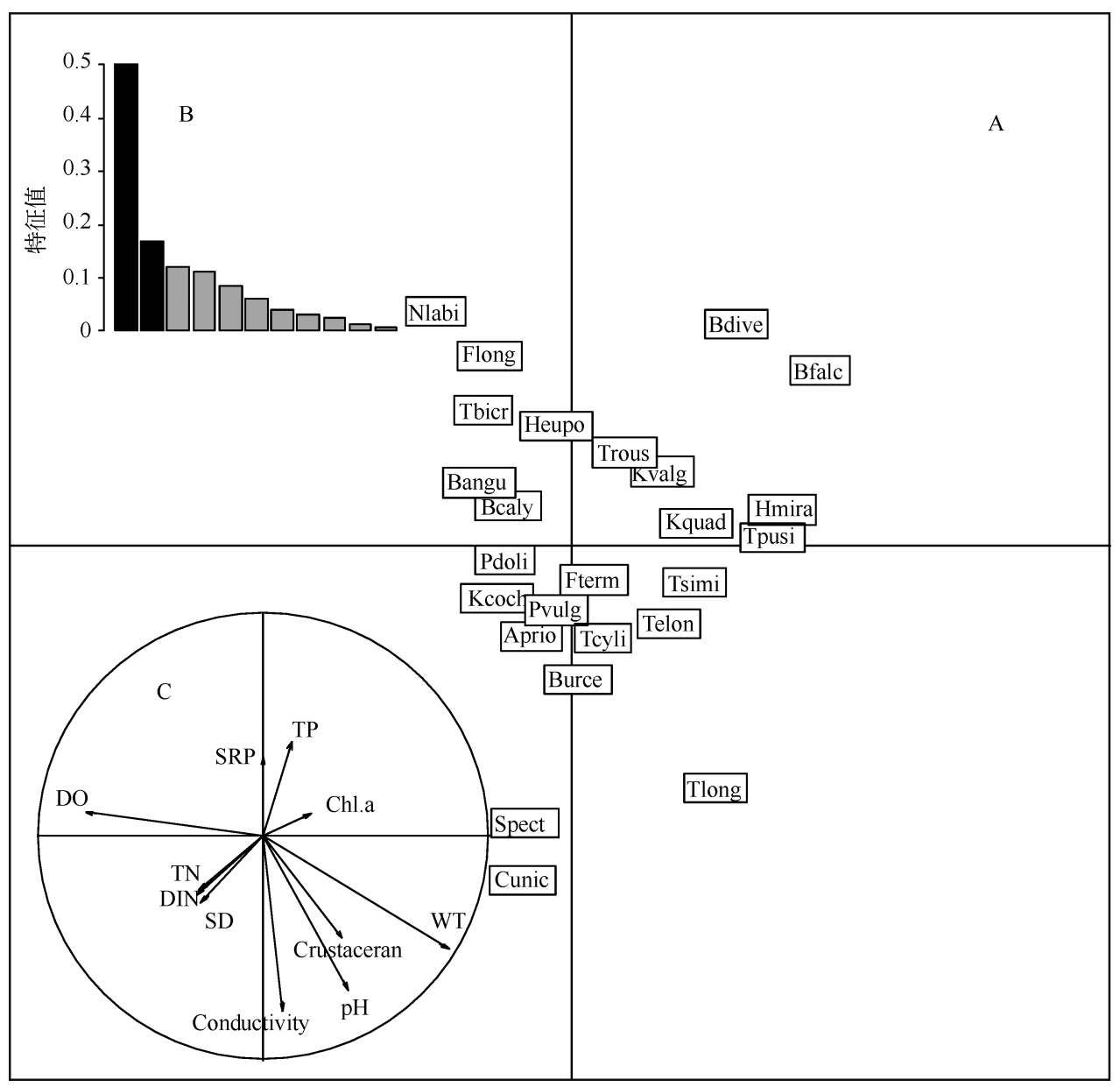

图 4 洪泽湖轮虫分布与环境因子之间的关系:

A. 轮虫的分布; B. 不同轴的特征根;C. 不同环境因子在 CCA 的矢量表达

Fig. 4 The relationship between rotifer distribution and environmental factors in Lake Hongze:

(A) Distribution of rotifer species; (B) Eigenvalues in the CCA;

(C) Canonical weights of each environmental factor

食物对轮虫的生长发育具有重要意义, 食物的多样性和不同种类食物的营养价值能明显影响轮虫的生长发 育 ${ }^{[29]}$. 通常情况下, 轮虫的密度与叶绿素 $\mathrm{a}$ 浓度呈正相关, 即轮虫密度随着浮游植物生物量的上升而增加 ${ }^{[30]}$. 但在 本文中却出现相反的结果, 洪泽湖夏季平均浮游植物生物量达到全年最高 ( Chl. a $=20.06 \mu \mathrm{g} / \mathrm{L}$ ), 但轮虫的 密度及生物量却最低. 造成这种现象的原因可能主要是食物资源的影响, 通常夏季蓝藻在富营养化浅水湖 泊易形成优势种, 由于蓝藻个体较大、可食性和营养价值较低以及有时会产生藻毒素, 可以影响浮游动物的 滤食能力 ${ }^{[31]}$, 本研究中洪泽湖夏季蓝藻密度占全部浮游植物密度的 $83.69 \%$, 成为优势种, 而春、秋、冬季蓝 藻密度所占的比例仅为 $45.21 \% 、 42.51 \%$ 和 $5.76 \%$ (未发表数据).

洪泽湖轮虫群落结构具有明显的空间异质性. 洪泽湖成子湖区、西南部湖区及东部沿岸带的轮虫从物 种数到密度、生物量均存在差异, 而产生这种差异的原因无疑是各区域水体营养状况的差异. 洪泽湖成子湖 区及西南部湖区是淮河、油河、濉河、成子湖等人湖口 ${ }^{[16]}$. 受上游污染的河流汇人洪泽湖内, 造成洪泽湖水体 营养物浓度升高. 在全部的 DIN 中, $\mathrm{NO}_{3}^{-}-\mathrm{N}$ 所占比例最高, 说明不合理的施肥方式等农业面源污染会对水体 DIN 产生影响. 另外, 成子湖区水流流速缓慢, 虽然水生植被覆盖率较高但结构单一, 水体营养水平较高, 进 
而证实各区域水体营养状况的差异是造成轮虫群落结构空间异质性的原因. 加之近年来在湖边湿地大规模 进行的围网养殖及围湖造田等活动, 破坏了湖泊生态系统的结构和功能, 加剧了水质污染及水体富营养化 程度, 严重影响湖泊轮虫群落的结构. 另外, 洪泽湖水位年际变化显著. 洪泽湖水位变化受多种因素制约, 如 降水、人湖河道水量等. 自 $1950 \mathrm{~s}$ 起修建的三河闸、高良涧等闸坝使洪泽湖成为完全人工调蓄的平原型水库. 春季关闸蓄水水位升高, 水生植被由于水位偏高、光照不足而影响其萌发和生长, 导致水生植物显著减少; 春季降水量增加, 环洪泽湖地区农业活动加剧, 营养盐随降水、地表径流进人洪泽湖, 致使春季 TN 及 DIN 含 量升高;夏季为保证防洪调蓄和农田灌溉而开闸放水导致水位下降,加之洪泽湖为浅水湖泊,水位的剧烈变 化及风浪的作用促使水体浑浊度增加、DO 下降. 水生植物的减少及水生态系统的不稳定性, 均会对洪泽湖 轮虫的群落结构产生影响 ${ }^{[14]}$.

CCA 分析结果 (图 4) 表明, WT、DO、电导率及氮、磷等营养物质会对轮虫的群落结构产生影响. 水温与 $\mathrm{CCA}$ 第一轴的正相关性最高, 而 DO 及 $\mathrm{SD}$ 与第一轴的负相关性较高, 因此 CCA 第一轴可以代表水体理化因 子的季节变化, 且温度可能是影响轮虫群落结构季节变化的主要原因. 电导率及氮、磷等营养物质与 CCA 第 二轴的相关性较高. 氮、磷等与水体营养状况相关, 电导率可以反映水体中离子浓度, 因此 CCA 第二轴可以 认为代表水体的营养状况.一般认为 TP 含量是判定水体富营养化程度的一个重要指标 ${ }^{[32]}$. 在浅水湖泊中, 水体的富营养化程度随着 TP 含量的升高而加剧, 并且鱼类的密度及生物量也随之升高, 因而对轮虫的群落 结构产生影响 ${ }^{[3-34]}$. 但也有一些研究表明, 在影响包括轮虫在内的浮游动物群落的环境因子中,氮的作用甚 至比磷重要. Wang 等 ${ }^{[35]}$ 在研究了长江流域 27 个浅水湖泊理化因子与轮虫群落结构的关系后得出, 轮虫密 度与水体无机氮含量呈显著正相关. 水体中可溶性无机氮和可溶性正磷酸盐的比值 (DIN: SRP) 也是评价影 响轮虫群落结构的重要指标 ${ }^{[36]}$, 比值的大小体现出不同的营养限制因子, 较高的 DIN: SRP 比值表明磷是最 重要的限制因子, 反之则氮为限制因子. 本研究中, 春、秋和冬季的 DIN: SRP 比值高于夏季, 表明磷是这 3 个 季节重要的营养限制因子, 而氮是夏季主要的营养限制因子. 从 CCA 分析结果 (图 4) 和优势种密度的季节 变化 (图 2) 来看,夏季的优势种如暗小异尾轮虫、奇异六腕轮虫和等刺异尾轮虫等与 WT、TP 及 $\mathrm{pH}$ 等相关 性较高, 而其余 3 个季节优势度均较高的螺形龟甲轮虫和长肢多肢轮虫集中在 TN 及 DIN 附近, 磷成为限制 因子. 另外, 水深也是影响轮虫群落结构的重要非生物因素之一. CCA 排序图很好地解释了轮虫群落与环境 之间的关系, 同时也反映出不同物种之间的生态位分化.一般认为富营养水体中常见的螺形龟甲轮虫、矩形 龟甲轮虫、暗小异尾轮虫和长三肢轮虫 ${ }^{[1]}$ 等在 $\mathrm{CCA}$ 排序图中与 $\mathrm{TP} 、 \mathrm{TN}$ 和 Chl. a 等相关性较高. 轮虫的种类 组成、时空分布及群落结构的变化受到环境因子的影响, WT、DO、Chl. a 和水体的营养状况等均是影响轮虫 群落结构的重要环境因子.

\section{4 参考文献}

[ 1 ] Sláde ček V. Rotifers as indicators of water quality. Hydrobiologia, $1983, \mathbf{1 0 0}$ ( 1 ) : 169-201.

[2] 胡春英. 保安湖浮游轮虫的动态研究. 水生生物学报, 2000,24(5):426-429.

[ 3 ] Offem BO, Samsons YA, Omoniyi IT et al. Dynamics of the limnological features and diversity of zooplankton populations of the Cross River System SE Nigeria. Knowledge and Management of Aquatic Ecosystems, 2009,393(2) :1-19.

[ 4 ] Fernando CH. Zooplankton, fish and fisheries in tropical freshwaters. Hydrobiologia, 1994,272 ( 1 ): 105-123.

[ 5 ] Mäemets A. Rotifers as indicators of lake types in Estonia. Hydrobiologia, 1983,104(1) :357-361.

[ 6 ] Duggan IC, Green JD, Shiel RJ. Distribution of rotifers in North Island, New Zealand, and their potential use as bioindicators of lake trophic state. Hydrobiologia, 2001 ,446/447:155-164.

[ 7 ] 李共国, 虞左明. 千岛湖轮虫群落结构及水质生态学评价. 湖泊科学, 2003,15(2):169-176.

[8] 黄祥飞,胡春英,伍焯田. 武昌东湖的轮虫. 水生生物学报,1985,9(2):129-142.

[ 9 ] Yoshida T, Urabe J, Elser JJ. Assessment of 'top-down' and 'bottom-up' forces as determinants of rotifer distribution among lakes in Ontario, Canada. Ecological Research, 2003 ,18(6) :639-650.

[10] Arnott SE, Vanni MJ. Zooplankton assemblages in fishless bog lakes: influence of biotic and abiotic factors. Ecology, $1993,74(8): 2361-2380$.

[11] Yang G, Zhong C, Pan H. Comparative studies on seasonal variations of metazooplankton in waters with different eutrophic 
states in Lake Taihu. Environmental Monitoring and Assessment, 2009,150(1) :445-453.

[12］葛绪广,王国祥. 洪泽湖面临的生态环境问题及其成因. 人民长江,2008,39(1):28-30.

[13］郝达平. 洪泽湖水环境现状评价及水污染分析. 江苏水利, 2005,11:31-33.

[14] 叶 春,李春华,王 博等. 洪泽湖健康水生态系统构建方案探讨. 湖泊科学,2011,23(5):725-730.

[15] 刘伟龙,邓 伟, 王根绪等. 洪泽湖水生植被现状及过去 50 多年的变化特征研究. 水生态学杂志, 2009,2(6):1-8.

[16] 《洪泽湖渔业史》编写组. 洪泽湖渔业史. 南京: 江苏科学技术出版社, 1990:138.

[17] 国家环境保护总局《水和废水监测分析方法》编委会. 水和废水监测分析方法:第 4 版. 北京: 中国环境科学出版 社, 2002 .

[18］黄祥飞. 湖泊生态调查观测与分析. 北京: 中国标准出版社,1999.

[19］章宗涉,黄祥飞. 淡水浮游生物研究方法. 北京:科学出版社,1991.

[20] 朱松泉,窦鸿身.洪泽湖一一水资源和水生生物资源. 合肥: 中国科学技术出版社,1993.

[21] 王家楫. 中国淡水轮虫志. 北京:科学出版社, 1961 .

[22] Devetter M. Influence of environmental factors on the rotifer assemblage in an artificial lake. Hydrobiologia, 1998, 387/ $388: 171-178$.

[23] May L. Rotifer occurrence in relation to water temperature in Loch Leven, Scotland. Hydrobiologia, 1983, 104 ( 1 ): 311-315

[24] Havens K, Beaver J. Composition, size, and biomass of zooplankton in large productive Florida lakes. Hydrobiologia, $2011,668(1): 49-60$.

[25] 杨丽丽, 周小玉, 刘其根等. 新疆布伦托海轮虫群落结构及其与环境因子的关系. 湖泊科学, 2011,23(5):806-812.

[26] Pavón-Meza EL, Sarma SSS, Nandini S. Combined effects of algal (Chlorella vulgaris) food level and temperature on the demography of Brachionus havanaensis (Rotifera) : a life table study. Hydrobiologia, 2005 ,546 :353-360.

[27] Elliott JA, Thackeray SJ, Huntingford C et al. Combining a regional climate model with a phytoplankton community model to predict future changes in phytoplankton in lakes. Freshwater Biology, $2005, \mathbf{5 0}$ (8):1404-1411.

[28] 胡菊香,吴生桂,陈金生等. 巢湖富营养化对轮虫的影响研究. 环境科学与技术,2007,30(12):16-18.

[29] 杨宇峰, 黄祥飞. 浮游动物生态学研究进展. 湖泊科学, 2000,12(1):81-89.

[30］杨桂军,潘宏凯,刘正文等. 太湖不同富营养水平湖区轮虫季节变化的比较. 湖泊科学,2007,19(6):652-657.

[31] Bernardi R, Giussani G. Are blue-green algae a suitable food for zooplankton? An overview. Hydrobiologia, 1990, 200/ $201: 29-41$.

[32] Jeppesen E, Jensen JP, Søndergaard M et al. Top-down control in freshwater lakes: The role of nutrient state, submerged macrophytes and water depth. Hydrobiologia, 1997,342/343:151-164.

[33] Wen XL, Xi YL, Qian FP et al. Comparative analysis of rotifer community structure in five subtropical shallow lakes in East China: role of physical and chemical conditions. Hydrobiologia, 2011,661(1) :303-316.

[34] Stefanidis K, Papastergiadou E. Influence of hydrophyte abundance on the spatial distribution of zooplankton in selected lakes in Greece. Hydrobiologia, 2010,656 (1):55-65.

[35] Wang S, Xie P, Geng H. The relative importance of physicochemical factors and crustacean zooplankton as determinants of rotifer density and species distribution in lakes adjacent to the Yangtze River, China. Limnologica-Ecology and Management of Inland Waters, 2010,40(1):1-7.

[36] Kagalou I, Kosiori A, Leonardos I. Assessing the zooplankton community and environmental factors in a Mediterranean wetland. Environmental Monitoring and Assessment, 2010,170(1):445-455. 